\title{
Estimating population parameters for the Critically Endangered Bermuda skink using robust design capture-mark-recapture modelling
}

\author{
Helena Turner, Richard A. Griffiths \\ Mark E. Outerbidige and Gerardo Garcia
}

\begin{abstract}
Reliably estimating population parameters for highly secretive or rare animals is challenging. We report on the status of the two largest remaining populations of the Critically Endangered Bermuda skink Plestiodon longirostris, using a robust design capture-mark-recapture analysis. Skinks were tagged with passive integrated transponders on two islands and captured on 15 sampling occasions per year over 3 years. The models provided precise estimates of abundance, capture and survival probabilities and temporary emigration. We estimated skink abundance to be $547 \pm$ SE 63.5 on Southampton Island and $277 \pm$ SE 28.4 on Castle Island. The populations do not appear to be stable and fluctuated at both sites over the 3 -year period. Although the populations on these two islands appear viable, the Bermuda skink faces population fluctuations and remains threatened by increasing anthropogenic activities, invasive species and habitat loss. We recommend these two populations for continued monitoring and conservation efforts.
\end{abstract}

Keywords Bermuda skink, capture-mark-recapture analysis, conservation, Plestiodon longirostris, population monitoring, reptile, robust design, survival

Supplementary material for this article is available at https://doi.org/10.1017/So030605318001485

\section{Introduction}

$\mathrm{M}$ any threatened species are cryptic, elusive and challenging to survey. The development of efficient survey methods to detect them is vitally important for conservation management. A wide variety of methods have been used in monitoring studies, including capturemark-recapture techniques to estimate abundance and

HeLENA TURneR (Corresponding author, (1) orcid.org/0000-0002-6067-888X) and Richard A. GrifFiths (10 orcid.org/0000-0002-5533-1013) Durrell Institute of Conservation and Ecology, School of Anthropology and Conservation, University of Kent, Canterbury, UK E-mail hturnerjsy@hotmail.com

Mark E. Outerbridge Government of Bermuda, Department of Environment and Natural Resources, Flatt's Village, Bermuda

Gerardo Garcia (10) orcid.org/0000-0002-3007-8998) Chester Zoo, Cedar House, Chester, UK

Received 28 July 2018. Revision requested 14 September 2018.

Accepted 6 December 2018. First published online 27 September 2019. survival (Krebs, 1999; Besbeas et al., 2002), which are critical determinants of population viability (White \& Burnham, 1999). Conventionally, marking is used to uniquely identify individuals in successive samples. For lizards, photographic identification using natural markings (Sacchi et al., 2010), tagging with passive integrated transponders (Germano \& Williams, 1993) and individual recognition from DNA sampling (Moore et al., 2009) have increased the utility and application of the capture-mark-recapture approach.

The Bermuda skink Plestiodon longirostris is the country's only extant endemic reptile (Bacon et al., 2006). The species primarily feeds on terrestrial and leaf litter arthropods such as ants and woodlice (Wingate, 1965) but also on a variety of other food sources such as prickly pear cactus Opuntia sp. and fruits (Wingate, 1965; Davenport et al., 1997, 2001; Edgar et al., 2010). Unlike many other reptiles, the skinks are scavengers with a keen sense of smell that attracts them to carrion (Garber, 1988; Davenport et al., 2001), and will make use of seasonally abundant food sources such as broken eggs, dead chicks and dropped fish from nesting colonies of the native white-tailed tropicbird Phaethon lepturus catesbyi and the endemic Bermuda petrel Pterodroma cahow (Garber, 1988; Edgar et al., 2010).

The skinks were once common throughout the islands of Bermuda but populations have undergone significant declines since the 1990 os when they were reportedly rarely seen on the mainland because of increased anthropogenic disturbance, habitat loss and degradation, and the introduction of invasive flora and fauna (Davenport et al., 1997; Glasspool \& Outerbridge, 2004). The species is now restricted to the edges of rocky coastal habitat and is categorized as Critically Endangered on the IUCN Red List (Conyers \& Wingate, 1996), with $<2,500$ individuals thought to be left on Bermuda (Edgar et al., 2010; Turner, 2019). Recent surveys have confirmed skinks at only 14 sites within nature reserves and offshore islands (Turner, 2019), and the continued threats are likely to have a major impact on the remaining fragmented and isolated populations.

We used a robust design model to monitor trends in abundance, survival, capture probabilities and temporary emigration of the two largest skink populations on Bermuda. The robust design model of Pollock (1982) is an extension of the Cormack-Jolly-Seber model and has become increasingly popular as it combines the advantages 
of the live-recapture model and the closed-capture models. The model and its assumptions are described in detail by Cormack (1968), Otis et al. (1978), Seber $(1982,1986)$ and Kendall et al. (1995). The current management plan for the Bermuda skink calls for monitoring every $3-5$ years (Edgar et al., 2010) but the last capture-mark-recapture surveys were undertaken in 2004, on Southampton Island, and the current status of the population was unknown. More frequent estimates of population parameters will be necessary to inform conservation management and future monitoring programmes.

\section{Study area}

This study was undertaken at two sites in Castle Harbour, Bermuda: the 0.8 ha Southampton Island and 1.4 ha Castle Island (Fig. 1). We chose these two sites because they are thought to harbour the largest known Bermuda skink populations, are both within protected nature reserves and are considered the most suitable areas for targeted conservation efforts. The islands are separated by a $330 \mathrm{~m}$ wide water channel and their abiotic factors are similar. Castle Island is closer to the main island (164 m) and faces more threats from invasive species and anthropogenic activities, which have been the main reasons for the skink's decline at this location. We surveyed additional sites across Bermuda but sample sizes were too small ( $<50$ individuals) to provide reliable estimates of abundance.

\section{Methods}

\section{Skink capture and marking}

We adapted methods from Davenport et al. (1997) and used a consistent survey protocol across the two locations. We used 65 glass jars (c. $240 \times 160 \mathrm{~mm}$, volume $4.5 \mathrm{l}$ ) as traps, set up in $10 \times 10 \mathrm{~m}$ grid networks (skink home ranges are c. $10 \mathrm{~m}^{2}$; Davenport et al., 1997). Traps were mounted at a $45-90^{\circ}$ angle, with rocks or vegetation placed at the opening so skinks could gain access. We used flagging tape to label each trap, recorded locations with a handheld GPS and used dried palmetto Sabal bermudana fronds and small towels to shade the traps. The pitfall traps were baited daily with $10 \mathrm{ml}$ of canned sardines, which were placed in a small sealed tea strainer to prevent consumption, which could affect recapture rates. We smeared $5 \mathrm{ml}$ of cod liver oil around the rim of each trap to prevent skinks escaping and to deter ants (Davenport et al., 1997). Traps were checked hourly during 11.00-16.00 and were then closed by removing the bait and turning the jar upside down to prevent accidental captures. We did not carry out surveys at temperatures $<21^{\circ} \mathrm{C}$ or when heavy rainfall or winds $(>25 \mathrm{~km} / \mathrm{h})$ were forecast because the lizards are less active under such conditions
(M. Outerbridge, 2015, pers. comm.) and because reaching the islands in adverse weather was challenging. On both islands we collected data over a 5 -day period per month during May-July of 2015, 2016 and 2017, resulting in a total of 15 sampling occasions per island and year. Each sampling occasion consisted of five trap checks per day, with a total trapping time of 75 hours per year per island (Supplementary Table 1).

We weighed all captured individuals and measured their snout-vent length, tagged unmarked animals and recorded tags of recaptured ones. All individuals in good health (excluding gravid females, and juveniles with a snout-vent length $<64 \mathrm{~mm}$ or body mass $<11.5 \mathrm{~g}$ ) were tagged with passive integrated transponders $(8 \times 1.4 \mathrm{~mm}, 30 \mathrm{mg}$, model ID162B FDX-B; Trovan, Douglas, Isle of Man) operating at a frequency of $134.2 \mathrm{kHz}$. Tags were inserted subcutaneously in either the left or right side of the body with a syringe implanter and 1.25-inch 14-gauge sterile disposable hypodermic needle. Prior to tagging, the injection site was wiped with antiseptic. Immediately after injection, a drop of cyanoacrylate glue was applied over the injection site to prevent tag loss and aid wound healing (Germano \& Williams, 1993; Gibbons \& Andrews, 2004). Once implanted, the tags were checked using a tag reader that revealed the individual's unique identification code. Even though tagging may induce temporary stress (Langkilde \& Shine, 2006), if inserted properly the tags do not otherwise affect the animals (Gibbons \& Andrews, 2004; Connette \& Semlitsch, 2012). Once processed, we immediately released individuals at the capture site.

\section{Statistical analyses}

We compiled capture histories as time series of binary values, with captures coded as 1 and non-captures as o, using a standard X-matrix format (Otis et al., 1978; Nichols, 1992). Rows represented capture histories of each captured individual and columns represented capture occasions.

We based the capture-mark-recapture modelling on a robust design model (Nichols, 1992), which assumes population closure between secondary sampling occasions or days (i.e. no births, deaths, emigration or immigration during each 5 -day sampling period), but assumes a population open to demographic changes between primary sampling occasions or years (over 3 years, 2015-2017; Fig. 2). The resulting encounter history consisted of 15 capture occasions with unequal time spacing; i.e. the 5 days were not always consecutive, nor was sampling undertaken on the same dates each year, because of weather conditions and logistical challenges.

\section{Model selection}

To monitor population trends between the two skink populations, we constructed the robust design model to estimate 

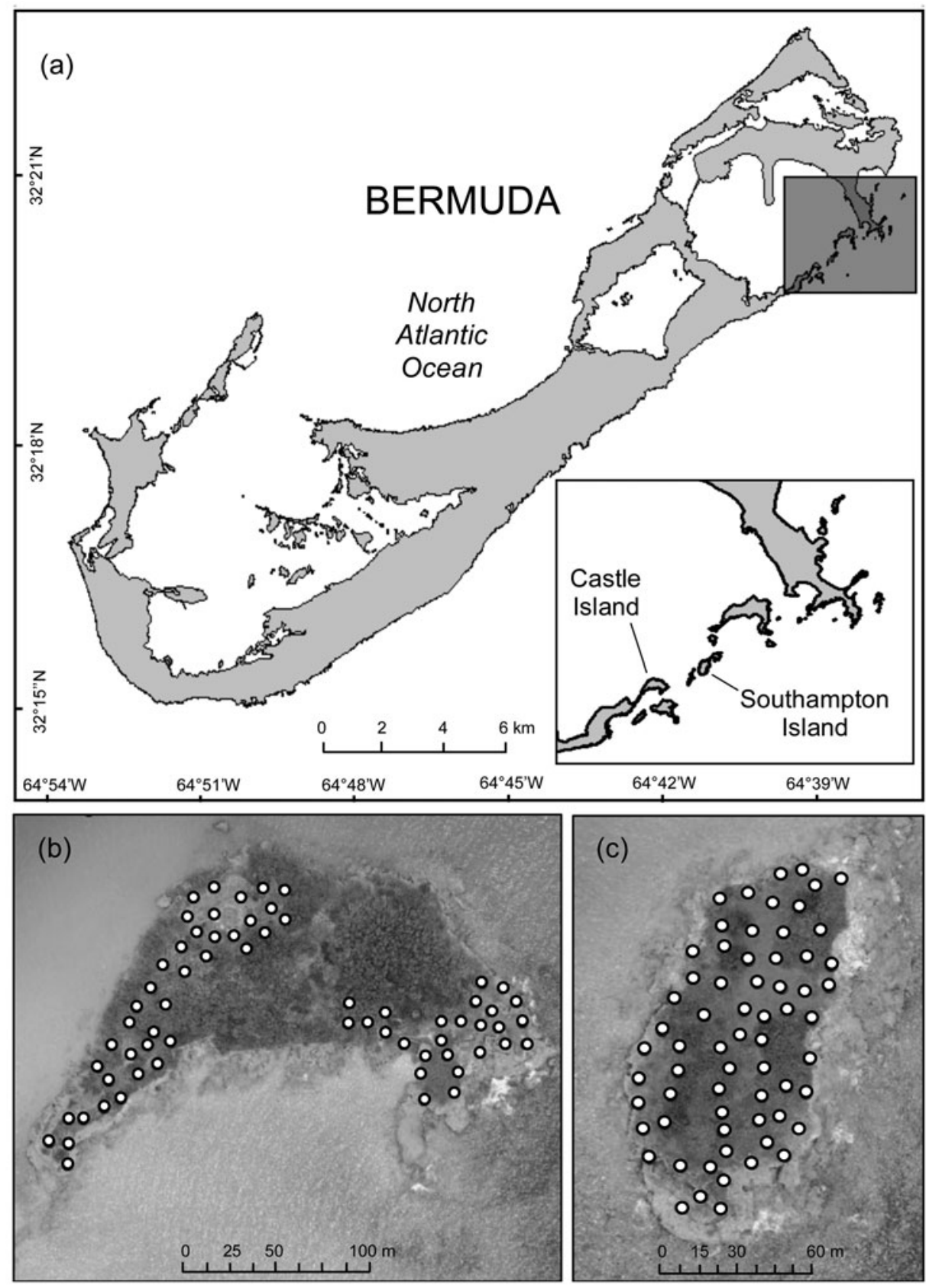

FIG. 1 (a) Bermuda with the locations of Castle and Southampton Islands within Castle Harbour, and locations of traps for the Bermuda skink Plestiodon longirostris on

(b) Castle Island and

(c) Southampton Island. the probability of survival $\varphi$, probability of capture $p$, temporary emigration $\gamma$ and population size $\mathrm{N}$, using the packages marked, descr and Rcapture in $R$ 3.4.3 (Rivest \& Baillargeon, 2014; R Core Team, 2016). We derived estimates of the demographic parameters using maximum likelihood estimates of the loglinear parameters with the $R$ function $g l m$ and calculated standard errors by linearization.

Ten loglinear models were used to account for the time $(t)$ and heterogeneity $(h)$ effects of capture probabilities on the two islands. These included the model with heterogeneity effects $M_{h}$ (the mean probability of capture), the model with time effects $M_{t}$ (the capture probabilities for each capture occasion), the model with both time and heterogeneity effects $M_{t h}$ (the mean probabilities of capture for each occasion) and the null model with no time or heterogeneity effects $M_{o}$ (the capture probability at any capture occasion; Rivest \& Baillargeon, 2014). The $M_{t h}$ and $M_{h}$ models were additionally fitted with four heterogeneity estimators: Chao (Chao, 1987), Poisson and Gamma (Rivest \& Baillargeon, 2007) and Darroch (Darroch et al., 1993). In addition, we tested temporary emigration (between 2015 and 2016; and between 2016 and 2017) for each island, because the probability of capturing an individual may vary between capture occasions. The models were compared based on their Akaike information criterion (AIC) values. 


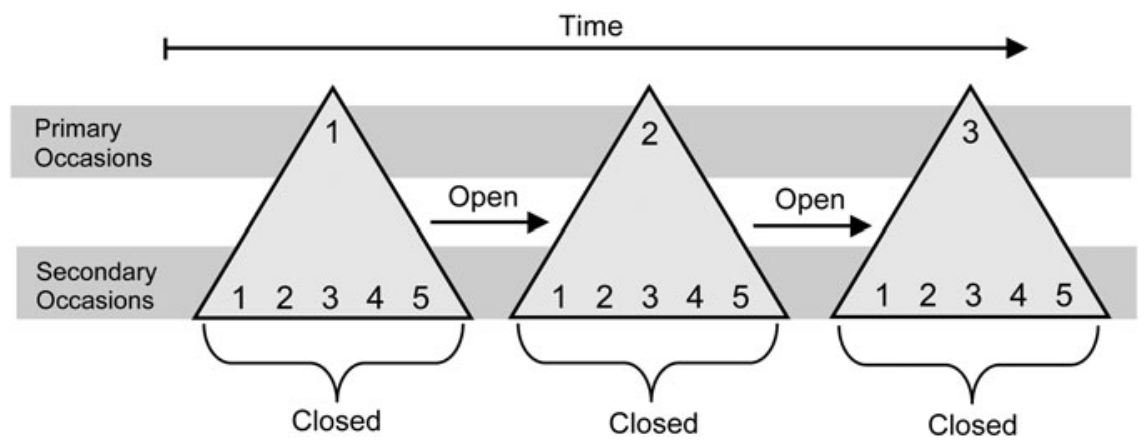

FIg. 2 Robust design example, with three primary trapping sessions each consisting of five secondary occasions.

\section{Results}

Over 3 years (2015-2017) we captured a total of 536 skinks at the study sites. We did not tag 47 individuals caught on Castle Island (43 were too small and four escaped) and 85 individuals from Southampton Island (62 were too small, four gravid and 19 escaped). Overall, 404 individuals were tagged and we used only these in further analyses. More than half of the marked skinks were recaptured over the 3 years: $52.6 \%$ (133 of 253 ) on Southampton Island and $58.3 \%$ ( 88 of 151 ) on Castle Island.

Applying a robust design model, the $M_{t h}$ model with Chao's estimator for each period had the lowest AIC and hence the best fit to the data for both islands (Table 1). According to the model, the estimated abundance was $\mathrm{N}=547 \pm \mathrm{SE} 63.5$ on Southampton Island and $\mathrm{N}=277 \pm \mathrm{SE}$ 28.4 on Castle Island. The robust design model provided precise abundance estimates, which were calculated for each location over 3 years (Fig. 3a). Estimates appeared to fluctuate between years on both islands. When comparing mean abundance between Southampton Island (mean $=253$ \pm SE 105) and Castle Island (mean $=164.4 \pm$ SE 86.9) estimates followed a normal distribution $(\mathrm{P}<0.05)$.

Estimates of annual capture probability derived using the model $M_{t h}$ were slightly higher on Southampton Island (mean $\mathrm{P}=0.50 \pm \mathrm{SE}$ 0.04) compared to Castle Island (mean $\mathrm{P}=0.42 \pm \mathrm{SE}$ 0.06). Capture probabilities were lowest in 2015 (Southampton Island: mean $\mathrm{P}=0.44 \pm \mathrm{SE} \quad 0.05$; Castle Island: mean $\mathrm{P}=0.34 \pm \mathrm{SE} 0.08$ ) and highest in 2016 (Southampton Island: mean $\mathrm{P}=0.57 \pm \mathrm{SE}$ 0.09; Castle island: mean $\mathrm{P}=0.54 \pm \mathrm{SE} 0.08$ ). The estimates were very precise (small standard errors) as a result of the relatively high capture probabilities (Fig. 3b).

Annual survival of skinks was higher on Southampton Island $(\varphi=0.58 \pm$ SE 0.21$)$ than on Castle Island $(\varphi=0.40 \pm$ SE o.09). Survival was lower at both sites from 2015 to 2016 but increased by $113.52 \%$ on Southampton Island and $58.72 \%$ on Castle Island from 2016 to 2017.

When comparing models, the best fit models for both islands included temporary emigration between years, indicating that a small number of individuals were not available for capture within the sampling areas. Between
2015 and 2016 temporary emigration was highest on Southampton Island but was not apparent on Castle Island. Between 2016 and 2017 temporary emigration was higher on Southampton but also occurred on Castle Island (Table 2).

\section{Discussion}

\section{Population trends over time}

This study provided precise estimates of abundance, capture and survival probabilities of a Critically Endangered lizard at two study sites. Our results demonstrate that passive integrated transponder tags provide a reliable method for long-term marking of lizards, and that a robust design model is effective for monitoring skink population trends.

Previous population estimates of the Bermuda skink were calculated using the simple Lincoln-Petersen method, which may be subject to bias (Seber, 1982). Using a temporary marking method (acrylic paint spots) can lead to some recaptures going undetected and the population size being overestimated as a result. In addition, previous studies did not account for juveniles (because of the trapping method used), and some were undertaken during the breeding season (May-June), with brooding females assumed to be unavailable for capture. Davenport et al. (1997) estimated the skink population on Southampton Island to be 414 in 1997, and Glasspool \& Outerbridge (2004) derived an estimate of 582 in 2004. On Castle Island, Hammond (2000) estimated 116 individuals in 200o. Population estimates were also calculated in 1998 at four other sites on Bermuda; 44 individuals on Palm Island in Sandys Parish, 52 on Inner Pear Island and 123 on Charles Island (both in St. George's Parish), and 124 at Spittal Pond, a mainland nature reserve in Smith's Parish (Raine, 1998; Wingate, 1998). Although these populations showed viable proportions of juveniles and adults with breeding potential at the time, there are now concerns for their long-term survival.

Estimating survival is important in demographic studies. For example, if skink recruitment is low, then persistence, repeated breeding and longevity may be key factors for 
TABLE 1 Model selection criteria for Bermuda skink Plestiodon longirostris capture-mark-recapture data from Southampton Island and Castle Island, Bermuda. Table shows skink abundance estimate $\pm S E$, Akaike information criterion (AIC), difference of AIC to best-performing model $(\triangle \mathrm{AIC})$, degrees of freedom $(\mathrm{df})$ and deviance for each model.

\begin{tabular}{|c|c|c|c|c|c|}
\hline Model & Estimate $\pm \mathrm{SE}$ & AIC & $\Delta \mathrm{AIC}$ & $\mathrm{df}$ & Deviance \\
\hline \multicolumn{6}{|c|}{ Southampton Island } \\
\hline$M_{\text {th Chao }}$ & $547.2 \pm 63.5$ & 571.53 & 0.00 & 32,740 & 332.39 \\
\hline$M_{t h}$ Poisson & $595.5 \pm 80.4$ & 574.31 & 2.78 & 32,743 & 336.17 \\
\hline$M_{t h \text { Gamma }}$ & $724.1 \pm 91.6$ & 574.44 & 2.91 & 32,745 & 340.30 \\
\hline$M_{\text {th Darroch }}$ & $719.0 \pm 86.3$ & 576.44 & 4.91 & 32,745 & 337.30 \\
\hline$M_{t}$ & $482.2 \pm 43.5$ & 589.20 & 17.67 & 32,746 & 357.06 \\
\hline$M_{h \text { Darroch }}$ & $718.7 \pm 86.2$ & 607.07 & 35.54 & 32,757 & 396.93 \\
\hline$M_{h \text { Poisson }}$ & $601.1 \pm 81.7$ & 609.85 & 38.32 & 32,755 & 395.72 \\
\hline$M_{h \text { Gamma }}$ & $722.5 \pm 91.3$ & 609.86 & 38.33 & 32,757 & 399.72 \\
\hline$M_{h \text { Chao }}$ & $555.2 \pm 65.0$ & 612.34 & 40.81 & 32,752 & 392.20 \\
\hline$M_{0}$ & $490.9 \pm 44.7$ & 622.94 & 51.41 & 32,758 & 414.80 \\
\hline \multicolumn{6}{|c|}{ Castle Island } \\
\hline$M_{\text {th Chao }}$ & 294 & 416. & 0.00 & & 249.36 \\
\hline$M_{t}$ & $274.7 \pm 27.5$ & 418.64 & 1.69 & 32,747 & 251.66 \\
\hline$M_{t h \mathrm{Gamma}}$ & $196.6 \pm 41.8$ & 420.45 & 3.50 & 32,743 & 247.36 \\
\hline$M_{\text {th Darroch }}$ & $183.6 \pm 24.1$ & 421.06 & 4.11 & 32,743 & 247.79 \\
\hline$M_{t h \text { Poisson }}$ & $175.2 \pm 30.7$ & 421.55 & 4.60 & 32,743 & 248.27 \\
\hline$M_{0}$ & $292.7 \pm 30.6$ & 521.41 & 104.46 & 32,759 & 380.12 \\
\hline$M_{h \text { Gamma }}$ & $193.8 \pm 37.1$ & 523.69 & 106.74 & 32,755 & 374.41 \\
\hline$M_{h \text { Chao }}$ & $294.8 \pm 31.5$ & 523.73 & 106.78 & 32,757 & 378.45 \\
\hline$M_{h \text { Darroch }}$ & $183.5 \pm 24.1$ & 523.99 & 107.04 & 32,755 & 374.71 \\
\hline$M_{t \text { Poisson }}$ & $176.9 \pm 32.5$ & 524.27 & 107.32 & 32,755 & 374.98 \\
\hline
\end{tabular}

recovery. Although previous surveys state the Bermuda skink may live for up to 21 years (Davenport et al., 2001), the survival estimates from our study suggest shorter life spans, similar to the 2-7 years observed in other closely related Plestiodon species in the wild (Clark et al., 2005). At both sites survival was low between 2015 and 2016, which resulted in a population decrease, followed by high survival between 2016 and 2017, which led to an increase in recruitment of the larger size classes. This was most likely the result of El Niño (a cyclic shift in atmospheric patterns; Cai et al., 2017) between 2015 and 2016. Although few major impacts such as tropical storms and hurricanes affected Bermuda during that time, precipitation was increased and winds were stronger compared to 2017 (Bermuda Weather Service, 2017). These conditions would have been unfavourable for skinks, with a reduction in seasonal food abundance and fewer opportunities for foraging, basking, breeding and incubating eggs. In turn, these factors may have driven the population fluctuations on the two islands.

Southampton Island continues to harbour the highest density of skinks on Bermuda, mostly because landing is prohibited and threats such as introduced predators and competitors (rats Rattus sp., kiskadee flycatchers Pitangus sulphuratus, cats Felis catus, anolis lizards Anolis sp. and yellow-crowned night herons Nyctanassa violacea), invasive
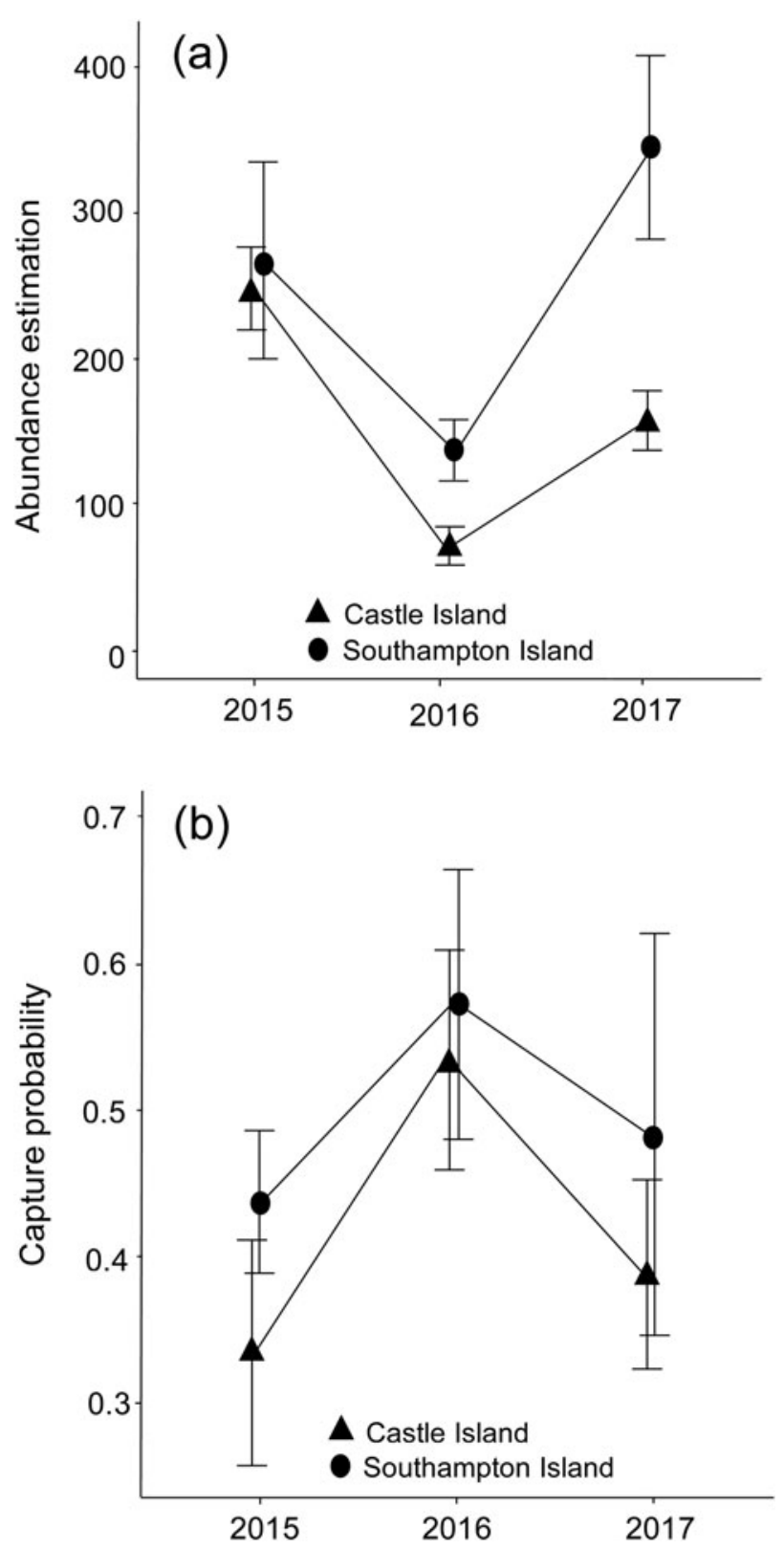

FIG. 3 (a) Comparison of $M_{\text {th }}$ Chao robust design model of Bermuda skink abundance estimates with standard error (vertical bars) on Southampton Island and Castle Island, Bermuda, during 2015-2017. (b) Comparison of $M_{t h}$ Chao robust design model of Bermuda skink capture probability with standard error (vertical bars) on Southampton Island and Castle Island, Bermuda, during 2015-2017.

plants (asparagus fern Asparagus densiflorus and casuarina trees Casuarina equisetifolia) and anthropogenic disturbance are largely absent. However, these threats are present on Castle Island and may explain why populations there take longer to recover from decreases (Fig. 3a). Studying population dynamics over a longer period may reveal whether these estimates are cyclic or stable and may uncover factors limiting population growth. 
TABLE 2 Estimated P. longirostris survival probability and temporary emigration, $\pm \mathrm{SE}$, on Southampton Island and Castle Island, Bermuda, during 2015-2017, using an $M_{\text {th }}$ Chao robust design model.

\begin{tabular}{lll}
\hline $\begin{array}{l}\text { Sampling } \\
\text { period }\end{array}$ & $\begin{array}{l}\text { Survival probability } \\
\varphi \pm \mathrm{SE}\end{array}$ & $\begin{array}{l}\text { Temporary emigration } \\
\gamma \pm \mathrm{SE}\end{array}$ \\
\hline $\begin{array}{l}\text { Southampton } \\
\text { Island }\end{array}$ & \\
2015-2016 & $0.372 \pm 0.08$ & $39.1 \pm 32.2$ \\
2016-2017 & $0.794 \pm 0.19$ & $36.7 \pm 49.8$ \\
Castle Island & & \\
2015-2016 & $0.309 \pm 0.06$ & $0.0 \pm 0.0$ \\
2016-2017 & $0.490 \pm 0.19$ & $26.0 \pm 11.9$ \\
\hline
\end{tabular}

\section{Meeting model assumptions}

Lizards may shift territories frequently during the breeding season (Ruby, 1978), or in response to fluctuations in food availability (Hews, 1993). Consequently, animals are more likely to be captured at some locations and times than others. This violates the standard assumptions of basic capture-mark-recapture models (Seber, 1982; Hammond, 1986). However, the interval between the primary capture trapping sessions (c. 1 year) was sufficiently long to ensure that gains (births and immigration) and losses (deaths and emigration) would occur and the sample size collected was large enough to detect heterogeneity and for the $M_{t h}$ model to fit well.

Temporary emigration may occur when a proportion of the population remains unavailable for capture. For example, skinks often spend a considerable time in rock crevices where they are difficult to capture. During the breeding season many females may be sedentary while guarding their nests (Glasspool \& Outerbridge, 2004) and are therefore unavailable for capture. If temporary emigration is not tested for it can lead to negatively biased population estimates, and model assumptions may be violated (Hammond, 1986, 1990).

For the management of small, threatened populations, the potential ramifications of underestimating (negative bias) or overestimating (positive bias) abundance are clearly important. As the robust design uses two levels of sampling it allows for more parameters to be estimated and for finer control over the relative precision of each parameter (Kendall \& Pollock, 1992; Kendall et al., 1995). The only major problem associated with the robust design is the large trapping effort required (Pollock, 1982); a minimum of 5 days at each site is recommended (Otis et al., 1978; Nichols, 1992) and intensive sampling can be costly. We therefore recommend this design for future capture-mark-recapture studies aimed at estimating reptile demographic parameters, particularly for species for which population declines need to be detected before they become critical.
Overall, the 10 different models in this study produced a broad range of abundance estimates, 175.2-294.8 individuals on Castle Island and 418.2-724.1 individuals on Southampton Island (both excluding juveniles). However, the abundance estimates based on $M_{t h}$ are reliable and using Chao's estimator provided lower bound conservative estimates that produced better fits than other estimators such as Darroch, Poisson and Gamma, which can be highly variable (Rivest \& Daigle, 2004), especially in small scale capture-mark-recapture studies (Chao, 1987). To estimate abundance with little bias, capture probability must be relatively high (Otis et al., 1978; Burnham \& Overton, 1979). Skinks had a moderate probability of capture on both Southampton and Castle Island (0.33-0.54 and 0.44-0.57, respectively), and therefore the trapping method is adequate to describe the dynamics of these populations. In general, the $M_{t h}$ estimator works well if most individuals are captured many times and when the population size is estimated to be $>100$ individuals (Otis et al., 1978).

In 2016, population sizes were low at both sites. However, at this time capture probability was highest. Although a considerable number of skinks were caught during this time (243 individuals in total), 53\% were recaptured individuals (compared to $12 \%$ in 2015 and $36 \%$ in 2017), which explains the lower abundance estimates.

\section{Conclusion}

The Bermuda skink receives the highest legislative protection under the Protected Species Act (2003), and the Government of Bermuda's Department of Environment and Natural Resources is committed to undertaking conservation activities that ensure the continued survival of this unique species.

Although we identified two relatively large populations, the fluctuations we observed suggest they remain vulnerable and may not be viable in the long term without management (e.g. creation of artificial burrows for both seabirds and skinks, predator control and habitat restoration), especially during periods of low abundance or when population growth is slow. We advise the continuation of passive integrated transponder tagging as a long-term marking method and that capture-mark-recapture surveys are undertaken annually, alternating between sites to monitor population trends across Bermuda. Additionally, we recommend using robust design models for evaluating population parameters when samples are taken over multiple days and years, as these can provide timely insights into population trends and the mechanisms driving them, with important implications for future conservation and research efforts.

Acknowledgements We thank the Government of Bermuda Department of Environment and Natural Resources for providing the necessary permissions and for their continued support; 
J. Maderios, A. Copeland, M. Meijas, N. Wellman, J. Labisko, S. Clayton-Green, D. Muldoon, N. Wright, J. Carney, D. D'Afflitto, M. Alonso, S. Massey, M. Shailer, P. Drew, R. Frith, K. Trott, R. Marirea, J.P. Rouja, P. Rouja and L. Thorne for assistance with fieldwork; R. McCrea and E. Matechou for assistance with statistical analyses; and the reviewers for their critiques. This research was funded by J. Summers Shaw, Chester Zoo, the States of Jersey, the British Herpetological Society and the Bermuda Zoological Society (Eric Clee Fund). This is Contribution \#278, Bermuda Biodiversity Project (BBP), Bermuda Aquarium, Museum and Zoo, Department of Environment \& Natural Resources.

Author contributions Analysis and writing: HT; experimental and statistical design: HT, RG; field work: HT, RG, MO, GG; revisions: RG, GG, MO

\section{Conflicts of interest None.}

Ethical standards This research abided by the Oryx guidelines on ethical standards, was approved by Chester Zoo and the University of Kent Research and Ethics Committee and was conducted under permits issued by the Government of Bermuda's Department of Environment and Natural Resources (DENR 15-06-12-27). Handling and tagging of skinks were undertaken in accordance with the conditions of the licence.

\section{References}

Bacon, J.P., Gray, J.A. \& Kitson, L. (2006) Status and conservation of the reptiles and amphibians of the Bermuda islands. Applied Herpetology, 3, 323-344.

Bermuda Weather Service (2017) Climate Data. Http://www. weather.bm/climate.asp [accessed 10 May 2017].

Besbeas, P., Freeman, S.N., Morgan, B.J.T. \& Catchpole, E.A. (2002) Integrating mark-recapture recovery and census data to estimate animal abundance and demographic parameters. Biometrics, 58, 540-547.

Burnham, K.P. \& Overton, W.S. (1979) Robust estimation of population size when capture probabilities vary among animals. Ecology, 60, 927-936.

Cai, W., Wang, G., Santoso, A., Lin, X. \& Wu, L. (2017) Definition of extreme El Niño and its impact on projected increase in extreme El Niño frequency. Geophysical Research Letters, 44, 11184-1119o.

Снао, A. (1987) Estimating the population size for capture-recapture data with unequal catchability. Biometrics, 45, 427-438.

Clark, K., Hendricks, A. \& Burge, D. (2005) Molecular identification and analysis of Borrelia burgdorferi sensu lato in lizards in the Southeastern United States. Applied Environmental Microbiology, 71, 2616-2625.

Connette, G.M. \& Semlitsch, R.D. (2012) Successful use of a passive integrated transponder (PIT) system for below-ground detection of plethodontid salamanders. Wildlife Research, 39, 1-6.

Conyers, J. \& Wingate, D. (1996) Plestiodon longirostris. In The IUCN Red List of Threatened Species 1996. Http://dx.doi.org/10. 2305/IUCN.UK.1996.RLTS.T8218A12900393.en [accessed 11 May 2018].

Cormack, R.M. (1968) The statistics of capture-recapture methods. Oceanography and Marine Biology Annual Review, 6, 455-506.

Darroch, S.E., Fienberg, G., Glonek, B. \& Junker, B. (1993) A three sample multiple capture-recapture approach to the census population estimation with heterogeneous catchability. Journal of the American Statistical Association, 88, 1137-1148.
Davenport, J., Hills, J., Glasspool, A. \& Ward, J. (1997) A Study of Populations of the Bermudian Rock Lizard (Skink), Eumeces longirostris, Cope (1861), on the Islands of Nonsuch and Southampton, Bermuda. Government of Bermuda, Department of Agriculture and Fisheries, Flatts, Bermuda.

Davenport, J., Hills, J., Glasspool, A. \& Ward, J. (2001) Threats to the Critically Endangered endemic Bermudian skink Eumeces longirostris. Oryx, 35, 332-339.

Edgar, P., Kitson, L., Glasspool, A. \& Sarkis, S. (2010) Recovery Plan for the Bermuda Skink Eumeces longirostris. Government of Bermuda, Department of Conservation Services, Flatts, Bermuda.

GARBER, S. (1988) Behaviour and ecology of the Endangered endemic Bermuda rock lizard (Eumeces longirostris). Rutgers University, New Jersey, USA.

Germano, D. \& Williams, D. (1993) Field evaluation of using passive integrated transponder (PIT) tags to permanently mark lizards. Herpetological Review, 24, 54-56.

Gibions, J.W. \& Andrews, K.M. (2004) PIT tagging: simple technology at its best. BioScience, 54, 447-454.

Glasspool, A. \& Outerbridge, M. (2004) A Population Re-Survey of the Bermuda Skink, Eumeces longirostris Cope (1861), on Southampton Island, Castle Harbour. Bermuda Zoological Society, Flatts, Bermuda.

HAMmOND, P.S. (1986) Estimating the size of naturally marked whale populations using capture-recapture techniques. Reports of the International Whaling Commission, 8, 253-282.

Hammond, P.S. (1990) Heterogeneity in the Gulf of Maine? Estimating humpback whale population size when capture probabilities are not equal. Reports of the International Whaling Commission, 12, 135-139.

Hammond, M.P. (200o) An Analysis of Bermuda Skink (Eucemes longirostris) Populations on Castle Island, Bermuda. Bermuda Aquarium, Museum and Zoo, Flatts, Bermuda.

Hews, D.K. (1993) Food resources affect female distribution and male mating opportunities in the iguanian lizard Uta palmeri. Animal Behaviour, 46, 279-291.

Kendall, W.L. \& Pollock, K.H. (1992) The robust design in capture-recapture studies: a review and evaluation by Monte Carlo simulation. In Wildlife 2001: Populations (eds D.R. McCullough \& R.H. Barrett), pp. 31-43. Elsevier Science Publishers, Barking, UK.

Kendall, W.L., Pollock, K.H. \& Brownie, C. (1995) A likelihood-based approach to capture-recapture estimation of demographic parameters under the robust design. Biometrics, 51, 293-308.

Krebs, C.J. (1999) Ecological Methodology. 2nd edition. Addison-Wesley Educational Publishers, Inc., Menlo Park, USA.

LANgkilde, T. \& Shine, R. (2006) How much stress do researchers inflict on their study animals? A case study using a scincid lizard, Eulamprus heatwolei. Journal of Experimental Biology, 209, 1035-1043.

Moore, J., Charles, A., Daugherty, H. \& Nelson, N.J. (2009) Large male advantage: phenotypic and genetic correlates of territoriality in tuatara. Journal of Herpetology, 43, 570-578.

Nich OLS, J.D. (1992) Capture-recapture models. Bioscience, 42, 94-102.

Otis, D.L., Burnham, K.P., White, G.C. \& Anderson, D.R. (1978) Statistical inference from capture data on closed animal populations. Wildlife Monograph, 62, 1-135.

Pollock, K.H. (1982) A capture-recapture design robust to unequal probability of capture. Journal of Wildlife Management, 46, 757-760.

R Core TeAm (2016) R: a Language and Environment for Statistical Computing. $R$ Foundation for Statistical Computing, Vienna, Austria.

RAINE, A. (1998) A study of the morphological differentiation, fluctuating asymmetry and the threats facing isolated 
populations of the critically endangered Bermuda Rock Lizard (Eumeces longirostris). MSc thesis, University College, London, UK.

Rivest, L.P. \& Baillargeon, S. (2007) Applications and extensions of Chao's moment estimator for the size of a closed population. Biometrics, 63, 999-1006.

Rivest, L.P. \& Baillargeon, S. (2014) R Capture: Loglinear models for capture-recapture experiments. $R$ package version 1.4-2. Http:// CRAN.R-project-org/package $=$ Rcapture [accessed 14 March 2019].

Rivest, L.P. \& Daigle, G. (2004) Loglinear models for the robust design in mark-recapture experiments. Biometrics, 60, 100-107.

Ruвy, D.E. (1978) Seasonal changes in the territorial behavior of the iguanid lizard Sceloporus jarrovi. Copeia, 3, 430-438.

Sacchi, R., Scali, S., Pellitteri-Rosa, D., Pupin, F., Gentilli, A. Tettamanti, S. et al. (2010) Photographic identification in reptiles: a matter of scales. Amphibia-Reptilia, 31, 489-502.
Seber, G.A.F. (1982) The Estimation of Animal Abundance and Related Parameters. 2nd edition. Macmillan, New York, USA.

Seber, G.A.F. (1986) A review of estimating animal abundance. Biometrics, 42, 267-292.

Turner, H. (2019) Population status and conservation of the Critically Endangered Bermuda skink. PhD thesis, University of Kent, Canterbury, UK.

White, G.C. \& Burnham, K.P. (1999) Program MARK: survival estimation from populations of marked animals. Bird Study, 46, 120-139.

Wingate, D.B. (1965) Terrestrial herpetofauna of Bermuda. Herpetologica, 21, 202-218.

WINGATE, R.S. (1998) A comparison of demography and morphological variation in two insular populations of the Bermuda rock lizard (Eumeces longirostris). MSc thesis, University of Wales, Swansea, UK. 